\title{
The Effects of Strategic Planning and Topic Familiarity on Iranian Intermediate EFL Learners' Written Performance in TBLT
}

\author{
Asghar Salimi \\ University of Maragheh, Maragheh, Iran; \\ Department of English, Islamic Azad University, Urmia Branch, Urmia, Iran \\ Email: Asgharsalimi356@gmail.com \\ Sima Fatollahnejad \\ Department of English, Islamic Azad University, Urmia Branch, Urmia, Iran \\ Email: sfatollahnejad@yahoo.com
}

\begin{abstract}
Task-based language teaching is recently the most frequently used method in second language instructions. The current study has focused on two main factors that have been proposed in TBLT, i.e. strategic planning and topic familiarity. It aims to investigate the effect of manipulation of strategic planning and topic familiarity on EFL written task performance. The participants were 80 intermediate female learners of English as a foreign language from a private language institute in Urmia, Iran. All of the written productions were coded using three measures covering accuracy, fluency and complexity. Using SPSS software, ANOVA have been used to analyze the collected data. The findings of this study carry significant pedagogical implications for task and syllabus designers, second language teachers and testers and also SLA researchers.
\end{abstract}

Index Terms - task-based language teaching, strategic planning, topic familiarity, accuracy, fluency, complexity

\section{INTRODUCTION}

For many years, language teaching and learning has been one of the most challenging and interesting areas of research. In recent years, tasks and task-based language teaching have played a central role in second language acquisition (SLA) research and language pedagogy and have attracted the interest of many second language teachers and researchers (Ellis 2003, 2005; Rahimpour, 2008; Skehan and Foster1999; Tavakoli and Skehan, 2005; Salimi and Dadashpour 2010; Mehrang and Rahimpour 2010; Tavakoli and Foster, 2008; Salimi et al, 2012; Kuhi et al, 2012; Salimi and Dadashpour, 2012).. In order to make a balance between focus on form and meaning in task-based approach to language instruction, the SLA researchers have suggested some proposals and one of them is providing planning time to ensure that the learners will focus on form and meaning at the same time (Skehan, 1996, 2003; Skehan and Foster, 1999; Yuan, 2001).

There are different types of planning in task-based language teaching. Ellis (2005) classifies task-based planning to two main kinds; pre-task planning and within-task planning. According to Ellis, pre-task planning includes rehearsal and strategic planning, and within-task planning is divided into pressured and unpressured.

Besides planning time, topic familiarity is also one of the factors that have been proposed in TBLT. Familiarity of the learners with the topics of the tasks which is the second independent variable of this study, as cited in Ellis (2003), impacts on the learners' propensity to negotiate meaning. Language users or language learners make use of their knowledge of the world to help them produce or comprehend the texts.

How planning affects second language production is of both theoretical importance to second language acquisition (SLA) researchers and of practical importance to language teachers (Ellis, 2005). Planning is assumed to be a strategy that frees learners from real-time communicative stress (Sangarun, 2001), frees up learners' attentional resources to attend to form (Van Patten, 1996), and allows learners to process the content and language of their planned production at a deeper and more meaningful level (Wendel, 1997). And pedagogical and practical importance of the present study is that it might help the language teachers to manipulate the tasks in a better way in TBLT. To this end, this study aimed to examine the impact of planning time and topic familiarity on the learners' writing to find some ways to improve the writing skill of EFL learners.

\section{LITERATURE REVIEW}

According to Ellis (2005), there are three central theoretical backgrounds for the study of planning in task-based research. They are Tarone's (1983) account of stylistic variation, models of speech production and writing, and 
cognitive models of L2 performance and language learning. Although different they are; these three theories have three main construct in common, i.e. attention and noticing, limited working memory capacity, and focus-on-form. As cited by Ellis (2005), one of the researchers who have been most influential in promoting the attention and noticing view is Richard Schmidt $(1990,1994,2000)$. He $(1990,1994)$ believes that conscious attention or noticing is essential for language learning. The second theory is limited working memory capacity. According to Ellis (2005), working or shortterm memory of the human beings has a limited capacity for processing information. It means that the extent to which language learners are able to attend to a specific system depends on the extent to which other systems are automatized. For example, when the learners use the working memory processing space to process the grammar, the attention that they can pay to lexical will be limited. And also there is a claim about the need for focus-on-form to acquire a second language especially in the case of adult learners. As cited in Ellis (2005), there are two rationales for this claim. Some of the researchers like Van Patten (1990) believe that it is difficult for the L2 learners to focus on meaning and form at the same time. The second rational for this claim is that interlanguage development can only take place if learners attend to form while they are engaged with meaning. According to Ellis (2005), providing the second language learners with the opportunity to plan the task before its real performance may lead to more attention and noticing, coping with limited capacity of working or short-term memory, focus on form along with meaning.

Also, the most influential theories in studies on oral and written task planning are Levelt's (1989) model of speech production and Kellogg's (1996) model of writing. Both models of production explicitly apply an information processing framework to an explanation of language production. The relevance of these models to studies on the effects of planning on oral and written language production is that they provide a basis for considering the components of language production on which learners focus while planning, and examine the effects planning strategies have on actual production (Ellis, 2003).

Besides planning time, the other independent variable of the current study was topic familiarity or prior knowledge of EFL learners about the topics of the tasks. From cognitive aspects, cognitive psychologists believe that knowledge is organized in the form of schemata (Long, 1990). Background knowledge or knowledge of the world is central to the way we understand language (Anderson and Lynch, 1988; Long, 1990). As cited by Sarandi (2010), the term prior information refers to a range of knowledge types, including our world knowledge, topic familiarity and previous experience in an area (content schemata), our expectation of the rhetoric of a text (formal schemata) (Carrel and Eisterhold, 1983) and the information received through earlier input, usually termed as co-textual information (Brown and Yule, 1983). By activating background knowledge, either in a top-down fashion via associative cognitive networks (Kintsch, 1998), reader or listener familiarity with text content appears to aid overall comprehension, in fact, in this process, the focus of the learners is on meaning not form of the written or spoken text.

\section{A. Research into Planning and Topic Familiarity}

Ellis (1987) found that "the amount of planning time available to the learner has a systematic effect on accuracy levels" (p. 12). Wendel in 1997 reported that strategic planning resulted in significant gains in complexity and fluency of language production but no significant results of greater accuracy were reported. Ortega (1999) concluded that planning before performing an L2 task can naturally promote a conscious focus on form. Kawauchi (2005) found that strategic planning had beneficial effects on complexity, accuracy and fluency of oral narratives. Yuan and Ellis (2003) also found that strategic task planning enhances grammatical complexity and fluency while unpressured within-task planning promotes accuracy and grammatical complexity. Mehrang and Rahimpour (2010) found that planning time had no effect on the accuracy and fluency of the learners' performances but led to more complex performances when participants performed the unstructured tasks. Yuan (2001) found that strategic planning enhances complexity of production, whereas accuracy is more enhanced under the unpressured within-task planning condition. Fluency, however, has been found to be equally enhanced through both planning conditions. Ellis and Yuan (2004) reported that whereas pre-task planning resulted in greater fluency and greater syntactic variety, the opportunity to engage in unpressured on-line planning led to increase accuracy. And also they found that strategic planning has a positive effect on complexity of written language productions. Ahmadi (2008) indicated that students improved their writing skills significantly after they were taught through strategic planning. Al-Humaidi (2008) found that the no-planning and strategic planning participants achieved statistically greater levels in one variable of fluency than the within-task planning participants. No statistically significant differences were found among the three groups in complexity and accuracy. Rahimpour and Nariman-Jahan (2011) reported that more fluent and complex performance was produced under planned condition by low proficiency learners, and quite the reverse, the high proficiency learners produced more fluent and complex performance under unplanned condition.

\section{B. Research into Topic Familiarity}

Chang (2006) revealed that while reading comprehension monitoring efforts were motivated by both topic familiarity and linguistic difficulty, inferencing events were primarily facilitated by topic familiarity. Pulido (2007) also found that familiarity of the learners with the topics of the reading tasks leads to better comprehension of the texts. Combs (2008) revealed that neither typographically enhanced text nor the topic familiarity training had a significant impact on the acquisition of form. Schmidt-Rinehart (1994) indicated that the subjects scored considerably higher on the familiar topic than on the new one. In a similar study, Sadighi and Zare (2002) provided some evidence in support of the effect 
of background knowledge on listening comprehension. Othman and Vanathas (2004) also indicated that topic familiarity has an influence on listening comprehension. Chang \& Read (2007) also revealed that providing background knowledge and familiarizing the learners with the listening tasks' topics is the most effective support for listening comprehension of the EFL learners. Rahimpour and Hazar (2007) revealed that the topic familiarity had a positive effect on accuracy and fluency of participants' oral output but it had a negative effect on complexity of their oral performance. Hayati (2009) concluded that familiarity of the language learners with culturally-oriented language material promotes the Iranian EFL learners' listening proficiency. Sarandi (2010) found that the experimental group did not perform significantly better than the control group.

As it can be concluded from the results of the above mentioned studies that have been done on the effects of topic familiarity or prior knowledge on L2 learners' reading and listening comprehension, in most of them, it has positive effects on reading and listening proficiency. However, according to Rahimpour and Hazar (2007), it is necessary to consider topic familiarity as a task feature in syllabus design and materials development. So, because of its importance in TBLT, there is a need to consider the effects of topic familiarity on four language skills.

And also, from the results of the studies on planning time, it seems that strategic planning has a positive effect on fluency and complexity, but the results for accuracy are mixed and are not very clear. And also, most of the researches have been done on the effects of planning time on oral production, but a few studies have been done on L2 learners' written performance.

In addition, most of the EFL learners, even the graduated ones have some difficulties in English writing. Difficulties of writing have been attributed to different factors, among which is the fact that Iranian learners have not been trained to practice pre-writing activities in their L1 and L2. Even, they do not know how to use the planning time to plan their writings before or during the task performance.

Furthermore, when the L2 learners are exposed with the tasks with familiar topics or when they have prior information about the topics of the tasks to be performed, in fact, they automatically focus-on-meaning rather than form (Long, 1990; Schmidt-Rinehart, 1994; Markham and Latham, 1987). And when the L2 learners are provided with the pre-task planning time before the task performance the learners focus on form rather than meaning in their planning time (Tsui and Fullilove, 1998). This study aimed to explore the effects of simultaneous manipulation of these two factors on written task performance which to the best of the researcher's knowledge has not been studied so far. Thus, the present study aimed to fill these gaps.

\section{RESEARCH QUESTION AND HYPOTHESES}

$R Q$ : What are the effects of strategic planning and topic familiarity on L2 learners' written performance in terms of accuracy, fluency and complexity in an EFL context?

HO: Simultaneous manipulation of topic familiarity and pre-task planning time does not have any significant effect on L2 learners' written performance in terms of accuracy, fluency and complexity.

H1: Familiar and planned group will outperform the other groups in terms of accuracy, fluency and complexity.

$H 2$ : Unfamiliar and unplanned group will produce less accurate, less fluent and less complex written products than other groups.

H3: Familiar but unplanned group will produce more fluent and complex but less accurate written products.

H4: Unfamiliar but planned group will produce more accurate but less fluent and less complex written products.

\section{METHODOLOGY}

\section{A. Participants}

Participants of the current study were 80 intermediate Language learners studying English as a foreign language at Atlas language institute in Urmia, Iran. All of them were female and from a bilingual community (Turkish as their mother tongue and Farsi as their L2).

\section{B. Accuracy Measure}

The number error-free T-units per T-units (Arent, 2003; Rahimpour, 2008; Salimi, Dadashpour, and Asadollahfam, 2011).

\section{Fluency Measure}

The fluency of the written production of the learners was measured by words per T-units (Ishikawa, 2006; Kuiken and Vedder, 2007, Salimi, Dadashpour \& Asadollahfam, 2011).

\section{Complexity Measure}

Complexity involves measuring both lexical and syntactic complexity. Lexical complexity of the written text was not taken into account because the learners were allowed to ask the researcher or their teacher about the intended lexical item. Regarding syntactic complexity, a measure of the ratio of the number of clauses to total number of $\mathrm{T}$-units was adopted (Mehnert, 1998; Ellis and Yuan, 2004; Salimi, Dadashpour, and Asadollahfam, 2011). 


\section{E. Data Collection Procedure}

The participants were randomly divided into 4 groups. Each group included 20 participants. The subjects of the first group were asked to write a composition about 'Nouruz' which was a familiar topic for Iranian students. And also this group was provided with pre-task or strategic planning time in which participants were given 10 minutes to plan for their writings prior to performing the task. Again, the second group like the first one was asked to write a composition about 'Nouruz'; but, the subjects of this group were not allowed to plan their writings before doing the task. The third group was required to write a composition about 'Christmas' which was an unfamiliar topic for them. This group like the first one was provided with 10 minutes of strategic planning time before and 20 minutes of time for doing the writing task. The fourth group like the third one was asked to write a composition about 'Christmas' without planning time.

\section{DAta AnAlysis AND Results}

ANOVA was employed to compare the means of accuracy, fluency and complexity of the written productions across the four groups.

\section{A. Testing the First and Second Hypotheses}

The mean differences of accuracy, fluency and complexity of the four groups are presented in table 1.

TABLE 1:

COMPARISON OF THE MEANS OF ACCURACY, FLUENCY, AND COMPLEXITY OF WRITTEN PRODUCTIONS ACROSS THE GROUPS

\begin{tabular}{|c|c|c|c|c|}
\hline & & $\mathbf{N}$ & Mean & Std. Deviation \\
\hline \multirow{5}{*}{ Accuracy } & F.P & 20 & 0.337 & 0.28446 \\
\hline & F.UP & 20 & 0.305 & 0.28391 \\
\hline & UF.P & 20 & 0.264 & 0.28735 \\
\hline & UF.UP & 20 & 0.2605 & 0.22137 \\
\hline & Total & 80 & 0.2916 & 0.26739 \\
\hline \multirow{5}{*}{ Fluency } & F.P & 20 & 7.405 & 1.97066 \\
\hline & F.UP & 20 & 6.4415 & 1.50998 \\
\hline & UF.P & 20 & 6.6515 & 1.83167 \\
\hline & UF.UP & 20 & 5.848 & 1.67612 \\
\hline & Total & 80 & 6.5865 & 1.81080 \\
\hline \multirow{5}{*}{ Complexity } & F.P & 20 & 1.511 & 0.48516 \\
\hline & F.UP & 20 & 1.4775 & 0.28392 \\
\hline & UF.P & 20 & 1.3015 & 0.25313 \\
\hline & UF.UP & 20 & 1.5800 & 0.46240 \\
\hline & Total & 80 & 1.4675 & 0.39181 \\
\hline
\end{tabular}

According to the above table, the mean of the fluency and accuracy in the planned and familiar group was higher than the fluency and accuracy of the written performances in the other groups. However, complexity mean of this group is not higher than the others.

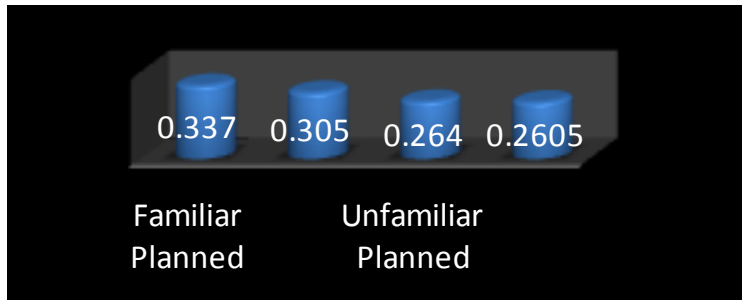

Figure 1: Comparison of the Mean of Accuracy of the Written Performances across the Groups

Based on the table 1 and figure 1, there was not a significant difference between the accuracy of the first and the other groups.

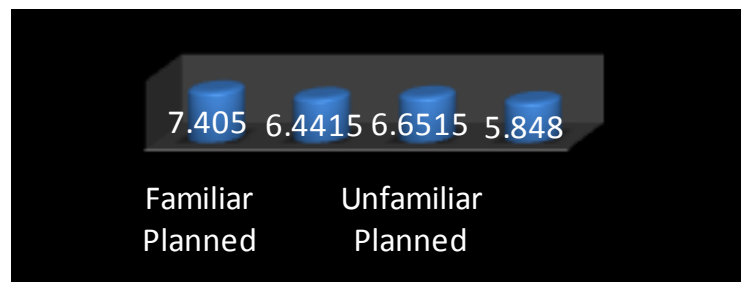

Figure 2: Comparison of the Mean of Fluency of the Written Performance across the Groups 
According to figure 2, the mean of the fluency in the planned and familiar group was higher than the fluency of the written performances in the other groups.

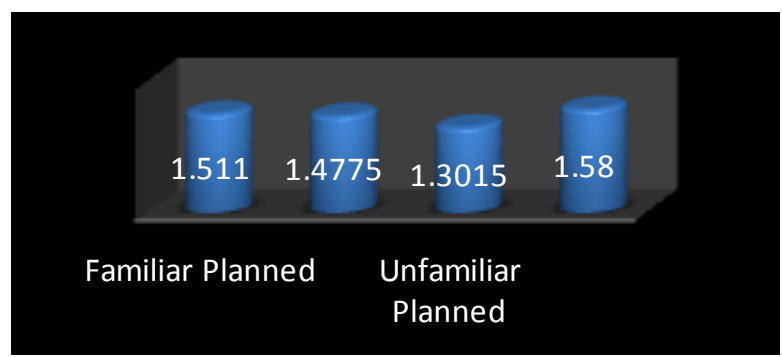

Figure 3: Comparison of the Mean of Complexity of the Written Performances across the Groups

According to figure 3, the mean of the complexity in the planned and familiar group was not higher than the complexity of the written performances in the other groups.

TABLE 2:

THE RESUlTS OF INFERENTIAL STATISTICS OF ANOVA FOR ACCURACY, FLUENCY, AND COMPLEXITY OF FOUR GROUPS

\begin{tabular}{|c|c|c|c|c|c|c|}
\hline & & Sum of Squares & df & Mean Square & $\mathbf{F}$ & Sig. \\
\hline \multirow{3}{*}{ Accuracy } & Between Groups & 0.079 & 3 & 0.026 & 0.361 & 0.781 \\
\hline & Within Groups & 5.569 & 76 & 0.073 & & \\
\hline & Total & 5.648 & 79 & & & \\
\hline \multirow{3}{*}{ Fluency } & Between Groups & 24.811 & 3 & 8.270 & 2.684 & 0.053 \\
\hline & Within Groups & 234.230 & 76 & 3.082 & & \\
\hline & Total & 259.042 & 79 & & & \\
\hline \multirow{3}{*}{ Complexity } & Between Groups & 0.844 & 3 & 0.281 & 1.895 & 0.138 \\
\hline & Within Groups & 11.284 & 76 & 0.148 & & \\
\hline & Total & 12.128 & 79 & & & \\
\hline
\end{tabular}

However, based on the inferential statistics, it was concluded that statistically topic familiarity and strategic planning did not have any significant effect on the accuracy, fluency and complexity of the language learners' written productions in this research. As a result, the first and the second hypotheses of this study are rejected and the null hypothesis is accepted.

\section{B. Testing the Third and Fourth Hypotheses}

Table 3 indicates the descriptive statistics concerning fluency and complexity of the four groups.

TABLE 3:

COMPARISON OF THE MEANS OF FLUENCY AND COMPLEXITY OF WRITTEN PRODUCTIONS ACROSS THE GROUPS

\begin{tabular}{lllll} 
& & N & Mean & Std. Deviation \\
\hline \multirow{4}{*}{ Fluency } & F.P & 20 & 7.405 & 1.97066 \\
\cline { 2 - 5 } & F.UP & 20 & 6.4415 & 1.50998 \\
\cline { 2 - 5 } & UF.P & 20 & 6.6515 & 1.83167 \\
\cline { 2 - 5 } Complexity & UF.UP & 20 & 5.848 & 1.67612 \\
\cline { 2 - 5 } & Total & $\mathbf{8 0}$ & $\mathbf{6 . 5 8 6 5}$ & 1.81080 \\
\hline \multirow{3}{*}{ F.P } & 20 & 1.511 & $\mathbf{0 . 4 8 5 1 6}$ \\
\cline { 2 - 5 } & F.UP & 20 & 1.4775 & $\mathbf{0 . 2 8 3 9 2}$ \\
\cline { 2 - 5 } & UF.P & 20 & 1.3015 & $\mathbf{0 . 2 5 3 1 3}$ \\
\cline { 2 - 5 } & UF.UP & 20 & 1.5800 & 0.46240 \\
\cline { 2 - 5 } & Total & 80 & 1.4675 & 0.39181
\end{tabular}

As it is clear in table 3, there were some differences in the means of fluency and complexity between four groups of this study.

TABLE 4:

THE RESULTS OF INFERENTIAL STATISTICS OF ANOVA FOR FLUENCY AND COMPLEXITY OF FOUR GROUPS

\begin{tabular}{lllllll} 
& & Sum of Squares & df & Mean Square & F & Sig. \\
\hline \multirow{3}{*}{ Fluency } & Between Groups & $\mathbf{2 4 . 8 1 1}$ & 3 & $\mathbf{8 . 2 7 0}$ & 2.684 & $\mathbf{0 . 0 5 3}$ \\
\cline { 2 - 7 } & Within Groups & $\mathbf{2 3 4 . 2 3 0}$ & 76 & $\mathbf{3 . 0 8 2}$ & & \\
\cline { 2 - 7 } & Total & $\mathbf{2 5 9 . 0 4 2}$ & 79 & & $\mathbf{1 . 8 9 5}$ & $\mathbf{0 . 1 3 8}$ \\
\hline \multirow{3}{*}{ Complexity } & Between Groups & $\mathbf{0 . 8 4 4}$ & 3 & $\mathbf{0 . 2 8 1}$ & & \\
\cline { 2 - 7 } & Within Groups & $\mathbf{1 1 . 2 8 4}$ & $\mathbf{7 6}$ & $\mathbf{0 . 1 4 8}$ & &
\end{tabular}

Based on figure 2 and figure 3, and also according to table 4, it was concluded that although there was a difference between the means of fluency and complexity of the planned and familiar group with the other groups; but, the difference was not statistically significant. 
Table 5 compares the accuracy means of the written performances across the groups.

TABLE 5:

COMPARISON OF THE MEANS OF ACCURACY OF WRITTEN PRODUCTIONS OF FOUR GROUPS

\begin{tabular}{lllll} 
& & N & Mean & Std. Deviation \\
\hline \multirow{4}{*}{ Accuracy } & F.P & 20 & 0.337 & 0.28446 \\
\cline { 2 - 5 } & F.UP & 20 & 0.305 & 0.28391 \\
\cline { 2 - 5 } & UF.P & 20 & 0.264 & 0.28735 \\
\cline { 2 - 5 } & UF.UP & 20 & $\mathbf{0 . 2 6 0 5}$ & $\mathbf{0 . 2 2 1 3 7}$ \\
\cline { 2 - 5 } & Total & $\mathbf{8 0}$ & $\mathbf{0 . 2 9 1 6}$ & $\mathbf{0 . 2 6 7 3 9}$
\end{tabular}

As it has been shown in this table and according to figure 1, there were some differences in the means of accuracy of the four groups.

TABLE 6:

THE RESUlTS OF INFERENTIAL STATISTICS OF ANOVA FOR ACCURACY FOR FOUR GROUPS

\begin{tabular}{lllllll} 
& & Sum of Squares & df & Mean Square & F & Sig. \\
\hline \multirow{3}{*}{ Accuracy } & Between Groups & $\mathbf{0 . 0 7 9}$ & 3 & $\mathbf{0 . 0 2 6}$ & $\mathbf{0 . 3 6 1}$ & $\mathbf{0 . 7 8 1}$ \\
\cline { 2 - 7 } & Within Groups & $\mathbf{5 . 5 6 9}$ & $\mathbf{7 6}$ & $\mathbf{0 . 0 7 3}$ & & \\
\cline { 2 - 7 } & Total & 5.648 & 79 & &
\end{tabular}

Table 6 shows the results of statistical analysis of ANOVA. The results revealed that there is not statistically significant difference between the accuracy means of the four groups. Thus, it can be concluded that familiarity of the learners with the topic of the task did not lead to more fluent and complex language and also, strategic planning time did not lead to more accurate language production. As a result, the third and fourth hypotheses of this study are rejected and again, the null hypothesis is accepted.

\section{DisCUSSION}

Considering the results of the data analysis on strategic planning and accuracy of EFL learners' written productions, it was found that strategic planning time did not have any significant effect on accuracy. Concerning the effect of planning time on accuracy, The findings of this study are in line with Wendel (1997), and Yuan and Ellis (2003, 2004), Foster and Skehan (1999), Ortega (1999), Mehrang and Rahimpour (2010), Yuan (2001), Al-Humaidi (2008), and Rahimpour and Nariman-Jahan (2011).

This production of less accurate when they were provided with strategic planning time can be attributed to the level of the participants in the current study. And also, language learners were not instructed about how they can use that time to plan their written performance. Thus, most of the learners did not know how to employ that pre-task time to focus and attend to form of the language that consequently leads to produce more accurate language.

Considering the results for fluency and complexity, the findings are in line with Kawauchi (2005) and Rahimpour and Nariman-Jahan (2011) who found that planning only promoted the complexity and fluency of the high-intermediate EFL group. However, considering the effects of strategic planning on complexity and fluency, the results of this research are in contrast with the findings of Wendel (1997), Foster and Skehan (1999), Mehnert (1998), Ortega (1999), Foster and Skehan (1999), Yuan and Ellis (2003), and Yuan (2001).

Concerning the effect of topic familiarity on complexity, the results are in line with Rahimpour and Hazar (2008), but they are in contrast in terms of fluency and accuracy. Also, the findings of this study are somehow in line with a research that has been conducted by Combs (2008), who found that topic familiarity did not have any significant effect on L2 learners' acquisition of form.

Some of the studies that have been done on the area of the impact of topic familiarity on reading comprehension found that it had a facilitative effect on reading comprehension, e.g. Chang (2006), and Pulido (2007). Therefore, the results are against the findings of these researches.

The results of this study which indicated that familiarity of the learners with the task topic did not have any significant effect on the learners' performance collaborates evidence for a study that was conducted by Sarandi (2010).

The findings of the current study are in contrast with the findings of the researchers like Schmidt-Rinehart (1994), Sadighi and Zare (2002), Othman and Vanathas (2004), Chang and Read (2006), and Hayati (2009) who found that familiarity of the learners with the topic led to more listening comprehension. In these researches the effect of topic familiarity was investigated on receptive skill (listening); meanwhile, this research examined its impact on writing that is a productive skill.

\section{PEDAGOGICAL IMPLiCATIONS}

The findings of this study have a number of pedagogical implications for SLA researchers, syllabus and task designers, EFL teachers, material developers and language testing specialists who are interested in task-based language instruction (TBLT). It may be desirable, the writing assignments or tasks to be arranged and taught according to their topic's familiarity to students. Teaching writing is more difficult and challenging than teaching other language skills. 
There is almost no explanation of the standards of good writing, neither is there a discussion of the self-regulation strategies that should be applied to accomplish a specific assignment.

In order to account for such shortcomings, as it was mentioned in discussion section, Harris \& Graham (1997) suggested a model called self-regulatory strategy development (SRSD) for teaching writing. Six stages that were defined in SRSD model are as follows: ("It" refers to the writing process using both self-regulation and specific writing strategies).

Develop background knowledge: The teachers help learners develop their pre-writing skills.

Discuss it: This stage involves a discussion between the teacher and the learners on the best strategies to accomplish specific assignments or tasks.

Model it: The teacher models how to use the strategy that was discussed in the previous stage, employing appropriate self-instructions.

Memorize it: In this step, the strategies discussed in the previous step and the self-evaluation notes are memorized.

Support it: Learners and teachers collaboratively practice the strategy using graphic organizers for the strategy and self-instruction to complete specific writing assignments.

Independent performance: Learners use the strategy independently at this stage.

\section{REFERENCES}

[1] Ahmadi, S. (2008). The effects of strategic planning on the improvement of Iranian EFL learners' writing skills in TBLT. Unpublished M.A. Thesis, Guilan University.

[2] Al-Humaidi, M. (2008). Planning in the writings of Saudi EFL learners at the college of languages and translation at KSU. Unpublished M.A. Thesis, King Saud University.

[3] Anderson, A. and Lynch, T. (1988). Listening. Oxford: Oxford University Press.

[4] Arent, R. (2003). Promoting revision and development in L2 writing through a combination- based curriculum. The Korea TESOL Journal, 6(1), 1-26.

[5] Brown, G., and Yule, G. (1983). Teaching the spoken language: an approach based on the analysis of conversational English. Cambridge: Cambridge University Press.

[6] Carrel, P.L., and Eisterhold, J.C. (1983). Schema theory and ESL reading pedagogy. TESOL Quarterly, 17 (4), 553-573.

[7] Chang, C. (2006). Effects of Topic Familiarity and Linguistic Difficulty on the Reading Strategies and Mental Representations of Nonnative Readers of Chinese. Journal of Language and Learning, 4 (4), 172-198.

[8] Chang, A. C., and Read, J. (2007). Support for foreign language listeners: its effectiveness and limitations. RELC Journal, 38(3), 375-395.

[9] Combs, C. (2008). Topic familiarity and input enhancement: An empirical investigation. Working Papers in TESOL and Applied Linguistics, 8(2), 1-51.

[10] Ellis R. (1987). Interlanguage variability in narrative discourse: Style shifting in the use of the past tense. Studies in Second Language Acquisition, 9, 1-20.

[11] Ellis, R. (2003). Task-Based Language Learning and Teaching. Oxford, Oxford University Press.

[12] Ellis, R. (2005). Planning and task performance in a second language. Amsterdam: Benjamins.

[13] Ellis, R., and Yuan, F. (2004). The effects of planning on fluency, complexity, and accuracy in second language narrative writing. Studies in Second Language Acquisition, 26, 59-84.

[14] Harris, K. R., Schmidt, T. and Graham, S. (1997). Strategies for composition and self-regulation in the writing process. University of Maryland, reprinted with permission from Teaching Every Child Every Day: Learning in Diverse Schools and Classrooms.

[15] Hayati, M. (2009). The Impact of Cultural Knowledge on Listening Comprehension of EFL Learners. English Language Teaching, 144-152.

[16] Ishikawa, T. (2006). The effects of task complexity and language proficiency on task- based language performance. The Journal of Asia TEFL, 3(4), 193-225.

[17] Kawauchi, C. (2005). The effects of strategic planning on the oral narratives of learners with low and high intermediate L2 proficiency. In Ellis, R. (Ed.) Planning and task performance in a second language. Amsterdam: John Benjamins.

[18] Kellog, R. (1996). A model of working memory in writing. In C. Levy and S. Ransdell (Eds.). The science of writing. Mahwah NJ: Lawrence Erlbaum.

[19] Kintsch, W. (1998). Comprehension: A paradigm for cognition. New York: Cambridge University Press.

[20] Kuhi, D., Salimi, A. and Shafaei, A. (2012). The effect of generic features of task on L2 learners' oral performance. Theory and Practice in Language Studies, 2(4), pp. 820-825.

[21] Kuiken, F., and Vedder, I. (2007). Task complexity and measures of linguistic performance in L2 writing. International Review of Applied Linguistics, 45(3), 261-284.

[22] Levelt, W. (1989). Speaking: From intention to articulation. Cambridge MA: The MIT Press.

[23] Long, D. R. (1990). What you don't know can't help you: An exploratory study of background knowledge and second language listening comprehension. Studies in Second Language Acquisition, 12(1), 65-80.

[24] Markham, P. L., and Latham, M. (1987). The influence of religion-specific background knowledge on listening comprehension of adult second language students. Language Learning, 37, 157-170.

[25] Mehnret, U. (1998). The effects of different length of Time for Planning on Second Language Performance. Studies on Second Language Acquisition, 20, 83-108.

[26] Mehrang, F. and Rahimpour, M. (2010). The impact of task structure and planning conditions on oral performance of EFL learners. Social and Behavioral Sciences, 2, 3678-3686.

[27] Ortega, L. (1999). Planning and Focus on Form in L2 Oral Performance. Studies in Second language acquisition, 21, 109-148. 
[28] Othman, J. and Vanathas, C. (2004). Topic familiarity and its influence on listening comprehension. The English Teacher, 8, 19-32.

[29] Pulido, D. (2007). The Effects of Topic Familiarity and Passage Sight Vocabulary on L2 Lexical Inferencing and Retention through Reading. Applied Linguistics, 28(1), 66-86.

[30] Rahimpour, M. (2008). Implementation of task-based approaches to language teaching. Research on Foreign Language Journal of Faculty of Letters and Humanities, 41, 45-61.

[31] Rahimpour, M., and Hazar, F. (2007). Topic familiarity effect on accuracy, complexity, and fluency of L2 oral output. The Journal of Asia TEFL, 4(4), 191-211.

[32] Rahimpour, M., and Nariman-jahan, R. (2011). The effects of planning on writing narrative task performance with low and high EFL proficiency. English Language Teaching, 4(1), 120-127.

[33] Sadighi, F. and Zare, S. (2002). Is listening comprehension influenced by the background knowledge of the learners? A case study of Iranian EFL learners. The linguistics Journal, 1(3), 110-126.

[34] Salimi, A. and Dadashpour, S. (2010). Task complexity and L2 learners' written performance. A paper presented at WCCES 14. Bogazici University, Istanbul, Turkey, 14-18 June.

[35] Salimi, A. and Dadashpour, S. (2012). Task Complexity and Language Production Dilemmas (Robinson's Cognition Hypothesis vs. Skehan's Trade-off Model). A paper accepted for presentation in WCES 2012, Barcelona University, Barcelona, Spain.

[36] Salimi, A., Dadashpour, S., and Asadollahfam, H. (2011). The Effect of Task Complexity on EFL learners' written performance. Social and Behavioral Sciences, 29, 1390-1399.

[37] Salimi, A., Shafaei, A. and Kuhi, D. (2011). The Impact of the generic features of tasks on L2 learners' written production. A paper presented in WCES 2012, Barcelona University, Barcelona, Spain.

[38] Sangarun. J. (2001). The effects of pre-task planning on foreign language performance. Doctoral thesis, University of Toronto, Canada.

[39] Sarandi, H. (2010). Content related support and listening comprehension: some limitations. Social and Behavioral Sciences, 2 , $5605-5611$.

[40] Schmidt-Rinehart, B. C. (1994). The effect of topic familiarity on second language listening comprehension. Modern Language Journal, 78(2), 179-189.

[41] Skehan P. (1996). A framework for the implementation of task-based instruction. Applied Linguistics 17(1), 38-62.

[42] Skehan, P., and Foster, P. (1999). The influence of source of Planning and focus of planning on task-based performance. Language Teaching Research, 3(3), 215-247.

[43] Skehan, P. (2003). Task-based instruction. Language Teaching. 36(1), 1-14.

[44] Tavakoli, P., \& Foster, P. (2008). Task design and second language performance: the effect of narrative type on learner output. Language Learning.58:2, 439-473.

[45] Tavakoli, p., and Skehan, P. (2005). Strategic planning, task structure, and performance testing. In R. Ellis (Ed.), Planning and task performance in a second language (pp. 239 - 277). Amsterdam: Benjamins.

[46] Tsui, A. B. M., and Fullilove, J. (1998). Bottom-up or top-down processing as a discriminator of L2 listening performance. Applied Linguistics, 19(4), 432-451.

[47] Van Patten, B. (1996). Input Processing and Grammar Instruction. Norwood NJ: Ablex.

[48] Wendel, J. (1997). Planning and Second Language Production. Unpublished Ed. D. Dissertation, Temple University Japan.

[49] Yuan, F. (2001). The effects of planning on language production in task-based language teaching. Doctoral thesis, Temple University.

[50] Yuan, F., and Ellis, R. (2003). The effects of pre-task planning and on-line planning on fluency, complexity, and accuracy in L2 monologic oral production. Applied Linguistics. 24(1), 1-27.

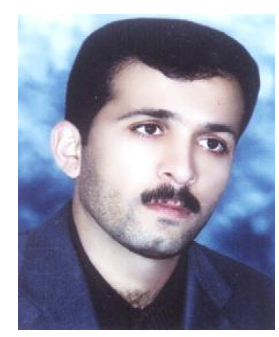

Asghar Salimi is a PhD candidate in applied linguistics at the University of Tabriz. He has been teaching English for over 10 years. He is currently a faculty member of Maragheh University. He has presented more than ten papers in different national and international conferences in different countries. His main areas of interest are task-based learning and teaching, syllabus design, and Second Language Acquisition (SLA).

Sima Fatollahnejad is M.A in TEFL. She received her degree from Islamic Azad University, Urmia Branch, Urmia, Iran. Her main areas of interest are task-based language teaching and planning time. 